\title{
Potential adaptation of Ginkgo biloba - comparative analysis of plants from China and Ukraine
}

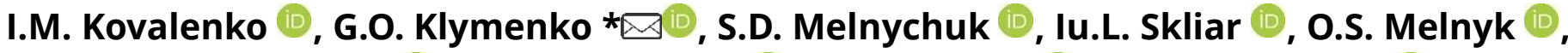

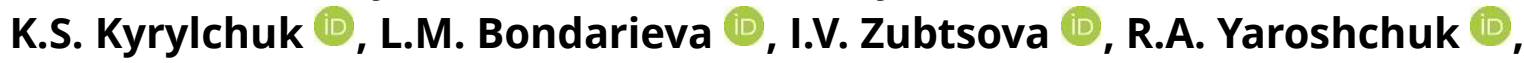 \\ S.V. Zherdetska
}

\author{
Sumy National Agrarian University, 160 G. Kondratyeva St, Sumy, 40021, Ukraine \\ Corresponding author email: annaklimenko2014@gmail.com
}

Received: 22.11.2020. Accepted: 26.12.2020

\begin{abstract}
Ginkgo biloba is one of the oldest relict plants in the existing seed plants. It is a historical heritage and living fossil. It is a world natural heritage unimaginable by human beings and a milestone in revealing nature's mysteries. The primary study areas with G. biloba plants are located in North-East Ukraine (Sumy region). A comparative analysis of the condition of seedlings in 2018 and 2019 was conducted. The plants were examined for the following morphological parameters: plant height, annual growth size, shoot diameter at the base, and the number of leaves. In two variants, about 100 plants were examined. The vitality analysis of seedlings with the establishment of their quality index is carried out. Studies of G. biloba leaves' morphological parameters from artificial plantations in Ukraine (Sumy) and natural plantations of China from the province were also carried out. Zhejiang province covers an area of 105,500 square kilometers and is located on the southeast coast of China. $118^{\circ} 01^{\prime}-123^{\circ} 10^{\prime} \mathrm{E}$ bounds Zhejiang Province, $27^{\circ} 02^{\prime}-31^{\circ} 11^{\prime} \mathrm{N}$, east of the East China Sea, north of Shanghai, which is China's largest city, and Qiantang River is the largest river in Zhejiang. Its climate is Subtropical monsoon. The average annual rainfall is $980-2000 \mathrm{~mm}$, the average annual sunshine is $1710-2100$ hours, and the average annual temperature is $15-18{ }^{\circ} \mathrm{C}$. We selected three $\mathrm{G}$. biloba groups for investigation and data collection. These three places are located west of Zhuji City, Zhejiang Province, about 5 kilometers apart. The G. biloba tree group in Guanshan, Lingshanwu, and Wuxie Village Zhejiang Province, China, were measured in 2019. The age of the trees ranges from 20 years to 500 years. The height is generally more than 15 meters, and the breast diameter is more than $20 \mathrm{~cm}$. In order to ensure the randomness of the data, we choose a tree every 50 meters. Studies have shown a statistically significant difference between leaves from China and Ukraine. Simultaneously, the leaf blade's size was more extensive in the leaves of G. biloba from artificial plantations in Ukraine. Morphometric analysis of G. biloba plantations (Ukraine) showed statistically significant differences between plant morphological parameters in 2018 compared to 2019 , which indicates the intensity of growth and the positive trends in plants' vegetative growth mass. Plant height increased from $26.68 \pm 1.01 \mathrm{~cm}$ in 2018 to $40.07 \pm 1.72 \mathrm{~cm}$ in 2019 , the annual increase, respectively, from $10.34 \pm 0.89$ to $13.90 \pm 0.92$. Such an indicator as the shoot diameter at the base has tripled (from $0.42 \pm 0.02 \mathrm{~cm}$ in 2018 to $1.41 \pm 0.02 \mathrm{~cm}$ in 2019). Differences between all morphological parameters have high statistical reliability (from 0.01 to 0.001 ). The differences were confirmed by the results of vitality analysis, which showed an increase in plant quality and their transition from equilibrium in $2018(\mathrm{Q}=0.300)$ to prosperous in $2019(\mathrm{Q}=0.465)$, which indicates optimal growth conditions and confirms the possibility of growing $\mathrm{G}$. biloba plantation method for obtaining medicinal raw materials in North-East Ukraine.
\end{abstract}

Keywords: relict plant, morphometric analysis, medicinal raw materials, cultivation technology

\section{Introduction}

Ginkgo biloba L. is an Endemic Tree Species in China. Only wild trees are found in natural forests in Tianmu Mountains (China) around the world. Most botanists believe that G. biloba plants originated in the Upper Carboniferous of the Paleozoic, about 2.8 to 350 million years ago (The IUCN..., 2018). From the late Jurassic to the Early Cretaceous (about 140 million years ago), G. biloba plants reached a period of high prosperity in their history. There are more than 20 genera and 150 species, almost all over the world. Now G. biloba has become a world-renowned "living fossil" and once again expanded its distribution to all parts of the world. It is a historical heritage and living fossil. It is a world natural heritage unimaginable by human beings and a milestone in revealing nature's mysteries (Seward, 1938). G. biloba is a rare bond between history and reality (Li, 1956).

G. biloba is used for seed, leaf, and timber. G. biloba seeds are rich in nutrients, both medicinal and edible. Since ancient times, it has been the best dry fruit for long-term health. It ranks fourth in the production of dried fruits in China. G. biloba leaves have high medicinal value (Singh et al., 2008; Bikram et al., 2008; Jacobs \& Browner, 2000; Mahadevan\& Park, 2008; Yoshikawa et al., 1999). Flavonoid glycosides, ginkgolides, and terpenoids can are extracted from G. biloba leaves. Pharmacological studies show that G. biloba preparations can dilate blood vessels, promote microcirculation and reduce cholesterol. It is the right drug for 
treating hypertension, cerebral arteriosclerosis, and cardiovascular diseases. Every $100 \mathrm{~kg}$ of air-dried G. biloba leaves (water content $12 \%$ ) can produce $1 \mathrm{~kg}$ of extracts (including flavonoids, picrolactone, terpenoids, and other eight ingredients), in addition to medicinal, can also be used as food, beverage, cosmetics additives. The male ginkgo trees are used to plant roads on both sides for garden decoration in China. The female ginkgo trees are planted as ginkgo plantations to harvest ginkgo (Chinese Flora..., 2006).

The wild G. biloba is only found in the western Tianmu Mountains of Zhejiang Province, about 30²0' N, 119 25' E, and scattered in broad-leaved forests valleys at altitudes of 300-1100 m. In this area, cutting of wild G. biloba should be strictly prohibited. There are $200 \mathrm{G}$. biloba trees more than 300 years. Most of these ancient trees are "multi-generational trees" with seedling roots and germination, called "double-dried ginkgo" in academic circles that are evidence of multiple generations of wild G. biloba in nature. According to statistics, there are seven trees with a diameter of more than 1 meter at breast height, the largest of which is 2.73 meters at root diameter. An ancient G. biloba tree with stem and fortified rocks has strengthened stem regeneration based on the stem at the cliff of 1000 meters above sea level. It grows on 500-1000 meter elevation, acidic (pH 5-5.5) yellow soil, and good drainage $(\mathrm{Xu}, 2001)$.

G. biloba has been widely cultivated in more than 50 countries. G. biloba is not very common in Ukraine, even in Southwestern Ukraine, the Odesa region, or Crimea (Kovalenko et al., 2018). The natural environment is there, especially the temperature precipitation, is more suitable for the growth of $G$. biloba trees.

Nevertheless, it can be found in some places such as Hoscha, Rivne oblast, where it was initially introduced in 1754 by introducing seedlings. Ten species grow in M.M. Gryshko National Botanical Garden, Kyiv, Ukraine, and some trees are in the Botanical Garden of Dnipro National University by Oles Gonchar. There is a G. biloba tree of 60 years old growing in Sumy Botanical Garden. There is a G. biloba tree more than 100 years old in the schoolyard of Kyiv Polytechnic University. The local government plans to gradually substitute all Chestnut trees in Kyiv with G. biloba due to its better growing qualities in urban areas.

G. biloba chichi (Fig.1) is specific germplasm of the ginkgo family and has become an ideal material for many scholars in biology, ecology, botany, forestry, and horticulture (Chauhan \& Maneesh, 2019).

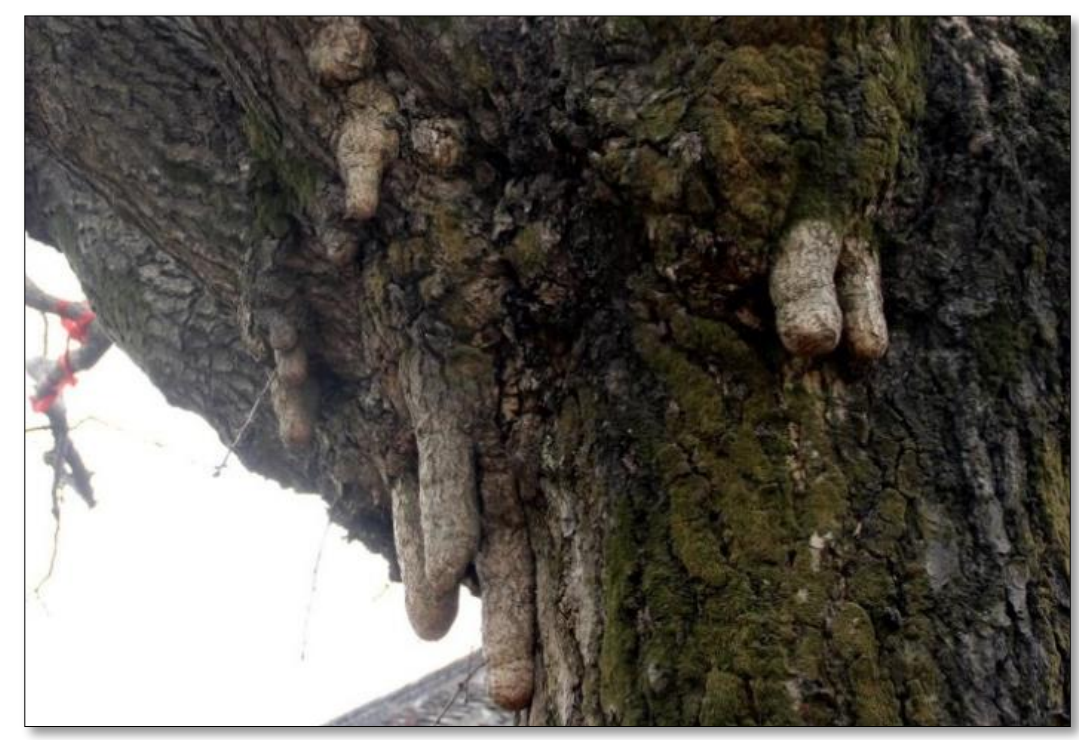

Fig. 1. Ginkgo biloba Chichi

Unlike other gymnosperms, one of the reasons is that G. biloba can germinate from root trees or woody stems and can germinate along the main stem of the wound. According to the study of Xing et al. (2013), chichi can survive G. biloba in three ways:

they are a place to produce and store buds that can germinate from the primary injury;

they are carbohydrates, and mineral nutrients are a storage place for these carbohydrates and Mineral nutrients can supply these buds to overgrow under stress and damage;

G. biloba, which grows on steep hillsides, functions as a climbing organ that allows plants to grab rocks.

When the top part encounters other strong and hard objects during deciduous milk growth, it changes its growth direction; it tends to grow downward when it passes through these objects.

The gingko grows moderately slowly, especially when it is first getting started. It can add between 30 and $60 \mathrm{~cm}$ to its height in a single growing season, and it is capable of eventually reaching heights between 15 and $25 \mathrm{~m}$. The world's largest ginkgo tree in China is a male plant with a tree height of 50 meters, a breast diameter of 4.79 meters (Cao, 2007).

Given the economic and medical value of G. biloba, the aim of this work was a comparative study of plants from natural plantations in China and from artificial plantations in Ukraine (Sumy, research fields of Sumy National Agrarian University) for successful distribution of this species in Ukraine.

\section{Materials and methods}

There are natural plantations of G. biloba in China. According to "Chinese ginkgo biloba", ancient ginkgo trees are widely 
distributed in Zhejiang Province, an important ancient G. biloba community concentration area and production area in China. Zhejiang Province covers an area of 105,500 square kilometers. It is located on the southeast coast of China. Zhejiang Province is bounded by $118^{\circ} 01^{\prime}-123^{\circ} 10^{\prime} \mathrm{E}, 27^{\circ} 02^{\prime}-31^{\circ} 11^{\prime} \mathrm{N}$, east of the East China Sea, north of Shanghai, which is China's largest city, and Qiantang River is the largest river in Zhejiang. Its climate is Subtropical monsoon. The average annual rainfall is $980-2,000 \mathrm{~mm}$, the average annual sunshine is $1710-2100$ hours, and the average annual temperature is $15-18^{\circ} \mathrm{C}$. The age of the trees ranges from 20 years to 500 years. The height is generally more than 15 meters, and the breast diameter is more than $20 \mathrm{~cm}$.

In Sumy, the plantation of G. biloba covers an area of 1.5 hectares. According to the Ukrainian Hydrometeorological Center (https://meteo.gov.ua/ua/33275), the average January temperatures varied from $-7.9^{\circ} \mathrm{C}$ in the north to $-7.1^{\circ} \mathrm{C}$ in the southwest of Ukraine. The average July temperature is from $+18.4^{\circ} \mathrm{C}$ in the north to $+19.9{ }^{\circ} \mathrm{C}$ in the southeast. The average annual rainfall is $550-600 \mathrm{~mm}$ in the north, $450 \mathrm{~mm}$ in the south. The relative humidity is $70 \%$. Thus, the climate in Ukraine is moderately continental with mild winters and moderately hot summers. The plants from Ukraine were of 4-5 years old, and the total number is about 4000 individuals.

The main factors affecting the growth of G. biloba are temperature and precipitation, and air humidity. The climate in Zhuji, China (Historical weather of Zhuji, DB/OL, was analyzed according to the Public service center of China Meteorological Administration (http://www.weather.com.cn/forecast/history.shtml?areaid $=101210502 \&$ month=9). Average January temperature is from $+1{ }^{\circ} \mathrm{C}$ to $+9{ }^{\circ} \mathrm{C}$; average July temperature is from +25 to $+34^{\circ} \mathrm{C}$, average annual rainfall is $1373.6 \mathrm{~mm}$; relative humidity is $82 \%$, the annual average temperature is $+16.3^{\circ} \mathrm{C}$. The daily average precipitation is 158.3 days. The annual average sunshine is about 1887.6 hours, and the annual sunshine percentage is $45 \%$. Comparison of average monthly climate parameters in Sumy (Ukraine) and Zhuji (China) is showed in Table 1.

Table 1. Climatic conditions (temperature and precipitation) in the studied regions (Sumy, Ukraine; Zhuji, China)

\begin{tabular}{lcccc}
\hline Months & \multicolumn{2}{c}{ Average temperature, ${ }^{\circ} \mathrm{C}$} & \multicolumn{2}{c}{ Average annual rainfall, mm } \\
Zhuji (China) & Sumy (Ukraine) & Zhi (China) \\
\hline January & & & 36.8 & 72.3 \\
February & -6.8 & 5.2 & 28.9 & 90.1 \\
Murch & -6.0 & 7.1 & 34.5 & 140.7 \\
April & -0.8 & 11.4 & 33.4 & 148.8 \\
May & 8.2 & 17.2 & 42.6 & 138.3 \\
June & 14.7 & 21.9 & 55.8 & 266.0 \\
Julay & 18.4 & 24.8 & 67.9 & 150.1 \\
August & 20.0 & 30.2 & 56.0 & 186.9 \\
September & 18.9 & 29.4 & 38.8 & 109.4 \\
October & 13.5 & 25.0 & 38.8 & 96.2 \\
November & 6.8 & 19.0 & 42.6 & 80.4 \\
December & 0.0 & 13.5 & 39.2 & 75.0 \\
\hline
\end{tabular}

(https://meteo.gov.ua/ua/33275, http://www.weather.com.cn/forecast/history.shtml?areaid=101210502\&month=9/)

There are 12 varieties of ginkgo in China, five of which are located in Zhuji City, Zhejiang Province. The three ginkgo groups for investigation and data collection were selected. These ginkgo groups are located west of Zhuji City, Zhejiang Province, about 5 kilometers apart. The ginkgo trees in Guanshan, Lingshanwu and Wuxie Village Zhejiang Province, China, were measured in 2019. We choose a tree every 50 meters to ensure the randomness of the data.

According to the growth of G. biloba and the difference in economic benefits (Zhao et al., 2010), "China Ginkgo Biloba" divides the cultivation areas of G. biloba into three categories (Fig. 1).

1) Suitable cultivation area - Annual average temperature is $12-20^{\circ} \mathrm{C}, \min \geq-20^{\circ} \mathrm{C}, \max \leq 40^{\circ} \mathrm{C}$, average annual rainfall may be more than $1000 \mathrm{~mm}$.

2) General cultivation area - Annual average temperature is $7-13^{\circ} \mathrm{C}, \min \geq-30^{\circ} \mathrm{C}$, $\max \leq 41^{\circ} \mathrm{C}$, average annual rainfall may be more than $500-1000 \mathrm{~mm}$.

3) Introduction area - Temperature and precipitation are beyond the scope of the first two categories, but from a practical point of view, G. biloba trees have strong environmental adaptability and can be tested.

A comparative analysis of G. biloba leaves from natural plantations in China (Zhejiang province), and leaves of trees growing in Sumy in the northeastern forest-steppe of Ukraine was carried out. Leaves in three variants of G. biloba plant cultivation in SNAU were studied: variant 1 (V1) - open ground without shading with typical conditions for Sumy region; variant 2 (V2) - open ground with shading (shading level $60 \%$ ) green agro-grid, climatic conditions are typical for Sumy region; variant 3 (V3) - in the greenhouse at the humidity of $60-80 \%$ and temperature not lower than $+27^{\circ} \mathrm{C}$ with shading about $60 \%$ by a green agro-grid. The leaves of one-year-old branches were used. Three parameters were investigated: leaves length, width, and surface area. The leaf area is closely related to its leaf plate's width and corresponds to the equation $y=-16.59+6.63 \times\left(r^{2}=0.99\right)$.

A comparative analysis of the condition of seedlings from Sumy National Agrarian University plantation in 2018 and 2019 was conducted. The plants were examined for the following morphological parameters: plant height, annual growth size, shoot diameter at the base, and the number of leaves. In two years, about 60 plants were examined. Plants from variant one were examined. 


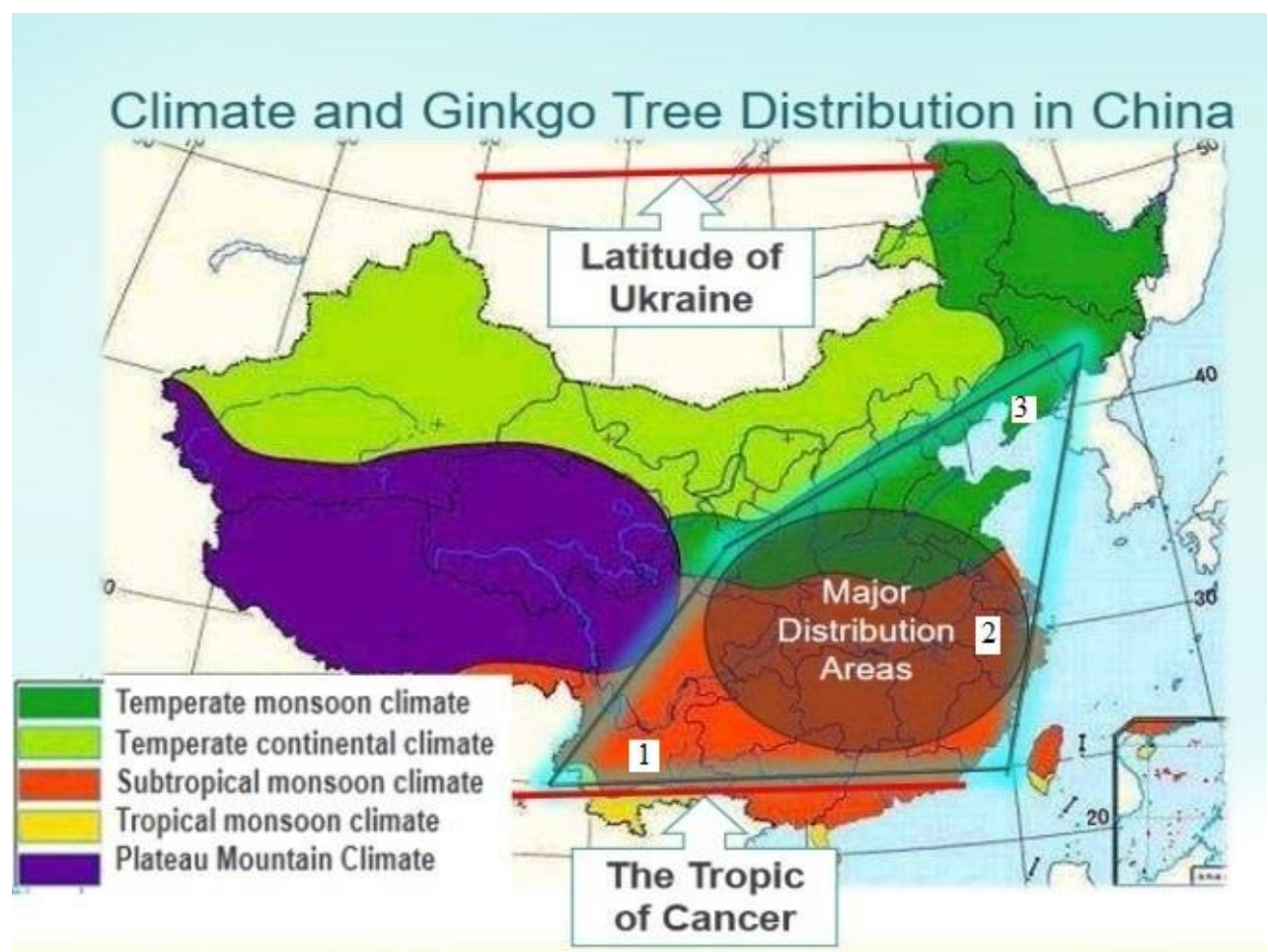

Fig. 2. Climate and G. biloba distribution in China. 1 - Suitable cultivation area, 2 - General cultivation area, 3 -Introduction area

Besides, we used analysis of variance and vitality analysis for the plants from variant one (V1). To determine G. biloba plantations' viability, vital analysis of seedlings was performed according to the classical scheme (Zlobin, 2018). The vitality of each seedling was evaluated by the value of the vitality Q coefficient, which ranged from 0 to 1.0. The seedlings were divided into three groups according to their vitality (viability): low, medium, or high vitality. The formula determined the vitality of the population (plantations) of G. biloba:

$$
Q=1 / 2(a+b),
$$

where $\mathrm{Q}$ is the vitality of the population in the range from 0 to 0.5 , $a$ and $b$ are the number of individuals of the corresponding vitality class.

The gradation of population vitality corresponds to the following Q values: depressed - from 0 to 0.167 , balanced - from 0.167 to 0.333 , and prosperous - from 0.333 to 0.500 .

We used statistical software Statistica 8.0 (Zlobin et al., 2013).

\section{Results}

A comparative analysis of the main morphometric parameters of G. biloba plants in 2018 and 2019 showed the following. All studied parameters (height of plants, annual increment, number of leaves, and diameter of the stem) were statistically significantly different from each other (Table 2).

Table 2. Main morpho-structural parameters of G. biloba plants grown by plantation method in Ukraine (Sumy, SNAU) ( $n=60)$

\begin{tabular}{lc}
\hline Parameter and year of investigation & ${\text { Mean } \pm \text { SE* }^{*}}^{\text {Height of plants, cm (2018) }}$ \\
Height of plants, cm (2019) & $26.68 \pm 1.01^{\mathrm{a}}$ \\
Annual increment, cm (2018) & $40.07 \pm 1.72^{\mathrm{b}}$ \\
Annual increment, cm(2019) & $10.34 \pm 0.89^{\mathrm{a}}$ \\
Number of leaves, pcs (2018) & $13.90 \pm 0.92^{\mathrm{b}}$ \\
Number of leaves, pcs (2019) & $16.45 \pm 2.11^{\mathrm{a}}$ \\
Diameter of stem, cm (2018) & $25.03 \pm 1.86^{\mathrm{b}}$ \\
Diameter of stem, cm (2019) & $0.42 \pm 0.02^{\mathrm{a}}$ \\
\hline
\end{tabular}

* the same letters in the column indicate statistically insignificant differences in the compared pair's means according to the Tukey criterion.

The statistical analysis confirmed the probability of the difference between the compared parameters. Thus, the height of plants increased by $45 \%$, annual growth by $30 \%$, the number of leaves increased by $45 \%$, and the shoot's diameter increased by three times in 2019 compared to 2018.

The variance analysis showed that statistically significant years differed in the two studied morphological parameters - plant height and stem diameter (Table 3). 
Table 3. Dispersion analysis of main morpho-structural parameters of G. biloba plants grown by plantation method in Ukraine (Sumy, SNAU)

Parameters F-Ratio P-Value

Height of plants, $\mathrm{cm}$ Annual increment, $\mathrm{cm}$ Number of leaves, pcs Diameter of stem, $\mathrm{cm}$

$\begin{array}{cc}36.6895 & 0.000{ }^{*} \\ 3.0680 & 0.0862 \\ 2.1492 & 0.1492 \\ 2369.45 & 0.000{ }^{*}\end{array}$

Note: * - parameters by which the seedlings of variants 1 and 2 statistically differed from one another.

A comparative analysis of G. biloba leaves' morphometric parameters is collected from trees growing in Ukraine (Sumy, SNAU) in three variants and locations in China (Guanshan, Lingshanwu, and Wuxiecum, Zhejiang Province) has been performed. We registered some variations in leaves parameters from Guanshan and Sumy (Table 4).

Table 4. Main morpho-structural parameters of G. biloba plants from China (Guanshan, Lingshanwu and Waxiecum) and Ukraine (Sumy, SNAU) (Guanshan: $n=100$; Lingshanwu: $n=100$; Waxiecum: $n=100$; SNAU: $n=130$ )

Leaves parameter

Value (mean \pm SE) \begin{tabular}{lr}
\hline Length, cm (Guanshan, China) & $5.30 \pm 0.08^{\mathrm{a}}$ \\
Length, cm (Lingshanwu, China) & $5.66 \pm 0.08^{\mathrm{a}}$ \\
Length, cm (Waxiecum, China) & $5.88 \pm 0.09^{\mathrm{a}}$ \\
Length, cm (V1, Sumy, Ukraine) & $4.98 \pm 0.07^{\mathrm{b}}$ \\
Length, cm (V2, Sumy, Ukraine) & $6.64 \pm 0.12^{\mathrm{c}}$ \\
Length, cm (V3, Sumy, Ukraine) & $7.35 \pm 0.08^{\mathrm{d}}$ \\
Width, cm (Guanshan, China) & $8.35 \pm 0.10^{\mathrm{a}}$ \\
Width, cm (Lingshanwu, China) & $8.85 \pm 0.10^{\mathrm{a}}$ \\
Width, cm (Waxiecum, China) & $8.83 \pm 0.10^{\mathrm{a}}$ \\
Width, cm (V1, Sumy, Ukraine) & $7.95 \pm 0.10^{\mathrm{b}}$ \\
Width, cm (V2, Sumy, Ukraine) & $9.28 \pm 0.06^{\mathrm{c}}$ \\
Width, cm (V3, Sumy, Ukraine) & $11.04 \pm 0.11^{\mathrm{d}}$ \\
Area, cm² (Guanshan, China) & $38.72 \pm 0.68^{\mathrm{a}}$ \\
Area, cm² (Lingshanwu, China) & $42.03 \pm 0.68^{\mathrm{a}}$ \\
Area, $\mathrm{cm}^{2}$ (Waxiecum, China) & $41.91 \pm 0.69^{\mathrm{a}}$ \\
Area, $\mathrm{cm}^{2}$ (V1, Sumy, Ukraine) & $36.11 \pm 0.08^{\mathrm{b}}$ \\
Area, cm² (V2, Sumy, Ukraine) & $44.92 \pm 0.62^{\mathrm{c}}$ \\
Area, $\mathrm{cm}^{2}$ (V3, Sumy, Ukraine) & $56.59 \pm 0.73^{\mathrm{d}}$ \\
\hline
\end{tabular}

Note: the same letters in the column indicate statistically insignificant differences in the compared pair's means according to the Tukey criterion.

Studies have shown slight differences in leaf blade area between samples of G. biloba leaves from China. On average, the leaf blade area of leaves from China was $40.89 \mathrm{~cm}^{2}$. The leaves of $G$. biloba from three variants in the research areas of SNAU differed significantly in the area, both from each other and from the leaves from natural plantations in China. The leaf blade's largest area was observed in the leaves of the variants with shading in the open ground and the greenhouse in Sumy National Agrarian University.

G. biloba leaves grown in open ground without shading (V1) had a leaf blade area smaller than the leaf area from China; the difference was about $12 \%$. The leaves collected from plants grown in open ground with shading (V2) had an area of leaf blade $13 \%$ larger than the area of leaves from China. The leaves of G. biloba plants grown in a greenhouse with shading (V3) had the largest leaf blade area among all the studied samples - compared to the leaves from China, the difference was about $30 \%$. Comparing the leaf samples from the three variants of $G$. biloba plant cultivation in SNAU, the dependence between the leaf blade area and growing conditions is visible: the plants with the cultivation variant in the conditions typical for natural conditions of the Sumy region in the open ground had the smallest area leaf blade by $30 \%$ compared to the first variant was observed in plants grown in open ground, but with the shading of G. biloba plantations (V2). The largest area (almost twice as large as leaves with V1 and $25 \%$ more than leaves with V2) was registered in the leaves from greenhouse and shading areas (V3).

A vitality analysis of $\mathrm{G}$. biloba plantations (V1) was performed (Table 5).

Variants differed by the year of planting seedlings in the ground. With the reliability of $92 \%$ and above, the vitality of $G$. biloba plantations was established. Plantations' viability increased in 2019 to a prosperous state compared to 2018, when vitality was assessed as equilibrium. Thus, we note a positive trend, which indicates the possibility of growing G. biloba plants in a plantation way in North-East Ukraine. 
Table 5. Vitality analysis of G. biloba agriculture populations, planted in 2018 and 2019

\begin{tabular}{lcccccc}
\hline $\begin{array}{l}\text { Year of } \\
\text { planting in the }\end{array}$ & \multicolumn{2}{c}{$\begin{array}{c}\text { Frequencies of vitality classes } \\
\text { ground }\end{array}$} & $\mathrm{a}$ & $\mathrm{C}$ & $\begin{array}{c}\text { Vitality, } \\
\mathrm{Q}\end{array}$ & $\begin{array}{c}\text { Statistical reliability, \% } \\
\text { Type of vitality }\end{array}$ \\
\hline 2018 & 0.200 & 0.400 & 0.400 & 0.300 & 92.5 & Balanced \\
2019 & 0.500 & 0.43 & 0.07 & 0.465 & 95.0 & Prosperous \\
\hline
\end{tabular}

\section{Discussion}

China is the country with the most abundant G. biloba resources, accounting for about $70 \%$ of the world total, ranking first in the world. G. biloba belongs to temperate deciduous broad-leaved forest species. Naturally, the plain and mountainous areas are dominated, and the altitudes cannot exceed 2,700 meters. G. biloba trees can grow in all kinds of soils (PH 4.5-8) except in saline-alkali soils. However, due to local climate differences, such as local topography, soil, water, and heat differences, the suitable areas are often concentrated in several counties or cities in a province, or some towns. Thus, the main producing areas of G. biloba in China are dispersed, massive, and flaky.

The heavy shearing should be carried out in the winter to promote the branching trees to have more branches and control the tree height within the operating height; the branches should be updated to remove some dense diseased branches and thin branches. The growing season is pruned, mainly in the late May, the topping of the new shoots above $30 \mathrm{~cm}$, effectively promote the secondary shoots and increase the number of branches and leaves; in autumn combined with the picking leaves to pay attention to the removal of the long branches (Chen, 2013).

Pest control. G. biloba has fewer diseases and insect pests. It is mainly susceptible to stem rot, leaf blight, silkworm moth, super-small leaf curler moth. Based on selecting suitable varieties, strengthening management, and timely treatment of disease plants, timely spraying of pesticides is necessary for prevention and control.

G. biloba grows slowly in the early stage and has a robust tillering ability. Female trees generally begin to bear fruit in about 20 years, and 500-year-old trees can usually bear fruit. Generally, the leaves germinate from late March to early April, blossom from early April to mid-April, seeds mature from late September to early October, and leaves fall from late October to early November (Ding, 1996; Rimkiene et al., 2017; Schmid \& Baltz, 2003).

In China, G. biloba growth about between $97^{\circ}-125^{\circ} \mathrm{E}, 21.5^{\circ}-41.77^{\circ} \mathrm{N}$. It spans the subtropical to temperate five climatic zones and various soil areas such as red soil, brown soil, and chestnut soil from south to north. Its vertical distribution is below 1000 meters in the sea, and it is ranged from 1,500 to 200 meters in the northwest and south.

The distribution of tree species reflects that it is a tree species with wide adaptability and strong resistance. G. biloba prefers a warm, cool, and humid climate to a cold, hot, and humid climate, so the eastern line of G. biloba distribution in China extends to the northeast the western line shifts to the south. The growth of forest trees is affected by environmental factors (Shi, 1992). The temperature indicators affecting the growth and development of G. biloba are mainly the annual average temperature, the average temperature in January, the average temperature in July, and the extreme minimum temperature. The annual average temperature of G. biloba growth interval in China is 7.5 to $21.8^{\circ} \mathrm{C}$, the average temperature in January is -12.3 to $14.6{ }^{\circ} \mathrm{C}$, and the average temperature in July is 16.3 to $29.0^{\circ} \mathrm{C}$, Extreme minimum temperature -32.6 to $0{ }^{\circ} \mathrm{C}$. However, G. biloba has a specific ability to hold cold. If the temperature is too low, the branches are frozen, and even the whole plant freezes to death. Significantly worse when it is dry at low temperatures and windy. G. biloba is a temperate deciduous fruit tree that requires a lowtemperature stage after falling leaves to facilitate dormancy. If the average temperature in January is too high, the winter is too warm. The low temperature required for warmth and dormancy is not satisfied, the development of buds is low, and growth and development are hindered. To the growth of G. biloba, the harmful of high temperature and precipitation in summer is less than the warmer winter. The average annual temperature can be 7.0 to $22.0^{\circ} \mathrm{C}$, the average temperature in January is -12.0 to $13.0^{\circ} \mathrm{C}$, the average temperature in July is 16.0 to $29.0^{\circ} \mathrm{C}$, and the extreme minimum temperature is higher than $-32.0^{\circ} \mathrm{C}$. It is regarded as the climate index of the G. biloba planting area.

After a long-term planting evolution, many excellent varieties have been bred in other regions of the world. For example, North Korea's G. biloba varieties have strong cold resistance and are more suitable for cultivation in cold areas. Japanese G. biloba has a high degree of improvement, which is conducive to improving Ukrainian G. biloba varieties.

G. biloba has a strong ability to adapt to the environment and resist stress. It usually has the characteristics of temperature and light. It is better to have a fertile sandy soil with good permeability. G. biloba has a wide range of adaptation to precipitation, and the annual precipitation of $330 \mathrm{~mm}$ to $1800 \mathrm{~mm}$ can satisfy G. biloba. Because G. bilobais a gymnosperm, has a neck egg and a large and multi-flagellated swimming sperm, like a humid climate, the annual precipitation in the main producing area is about $1000 \mathrm{~mm}$. The precipitation during flowering has a significant impact on the results of G. biloba.

G.biloba is dioecious and wind-flowered. If it encounters continuous rain and rain, it will affect the result because of the first bad. Long periods of rain and snow afterward can be detrimental to the growth of G. biloba, which can lead to broken branches. The air of China G. biloba distributor is relatively moderate between $50 \%$ and $80 \%$, and the relative humidity of the central economic zone is higher, about $74-80 \%$. If the precipitation is scarce, the air humidity is low, and the climate is dry, which will cause the tree to grow slowly.

The soil factors affecting the growth and development of G. biloba include soil permeability, pH value, groundwater level, texture, soil thickness, and fertility. The previous three have a more significant impact (Gopichand, 2015; Guo et al., 2016).

The cultivation of $G$. biloba should be selected and controlled according to the botany characteristics of G. biloba, combined with regional differences (Cai et al., 2018). In the land selection, first, the site conditions for the use of the G. biloba tree in the leaf area are required to be flat, with good irrigation and drainage conditions, fertile loam or sandy loam; in the saline-alkali land, 
the mountainous land is not suitable for the use of G. biloba garden. The planting time can be spring or autumn. (Cao, 2007). To obtain high-yield, high-quality G. biloba leaves, it is necessary to strengthen soil management and an adequate fertilizer and water supply. Soil management is mainly for weeding. The artificially trimmed leaves are mainly planted with G. biloba gardens. To facilitate leaf picking and tree management, the picker trees should adopt a short dry, low-crown cup or round shape, and the trunk height should be controlled below $50 \mathrm{~cm}$ that takes 3 to 5 times of cultivation to form a cluster-shaped canopy. Under natural conditions, it takes more than 20 years for $G$. biloba to grow from planting to fruiting, and it takes 40 years to reach the fruiting stage.

The biological characteristics of G. biloba, in a broad sense, refer to the various characteristics of survival and growth of G. biloba. Generally, these characteristics are divided into two parts: one is the general law of growth and development of G. biloba itself, which is called biological characteristics; the other is the correlation between the cultivation and distribution of $G$. biloba and environmental conditions, which is called ecological characteristics (Cao, 2007).

Main ecological values of G. biloba (Su \& Klymenko, 2019):

- $\quad$ Ginkgo's canopy is huge, the leaves are thick, and the temperature is lowered in summer.

- $\quad$ Strong ability to sprout can be asexual reproduction of all life. The root system is developed, and the vitality is tenacious. Even if the trunk and main branches are destroyed, new trunks can still be grown.

- $\quad$ G. biloba is resistant to soot and harmful gases and has strong radiation resistance. Thus, it is widely planted in chemical plants and cities.

- G. biloba is drought-tolerant and can be planted in areas with severe soil erosion, maintaining soil and improving soil.

- $\quad$ G. biloba cultivation as a farmland protection tree can improve the ecological environment and promote grain production. We know that Zhuji is a typical Suitable cultivation area; Zhuji is also the main cultivation area of Chinese G. biloba. Ukraine's annual average temperature and minimum temperature are lower than the average cultivated area, and the humidity is low, so Ukraine belongs to the introduction area.

According to the experience of introduction in China's domestic regions, all Ukraine can be divided into low-temperature and arid regions in the southeast (LA), low-temperature and semi-arid regions in the central part and northern of the country (LS), and low-temperature and high-salt areas along the Black Sea (LH) (Kovalenko et al., 2019).

Precipitation and irrigation should be considered first in the introduction in LA area. It is not suitable for the introduction in the extremely arid area. Other areas can try small-scale introduction, mainly for garden viewing.

In LS area, the annual precipitation is generally more than $450 \mathrm{~mm}$. The introduction scale is determined according to precipitation and atmospheric humidity. We can try to use the greenhouse to cultivate low varieties of G. biloba economic forest and harvest fruits.

LH area is generally located in the Black Sea coast of southern Ukraine, with a high annual average temperature and precipitation conducive to G. biloba. In some areas with high salt content (0.2-0.3 \%), soil improvement should be carried out first, and the survival rate will be significantly improved. G. biloba tree can regulate ecology and control soil salt in coastal farmland.

The main factor affecting the growth of Ukrainian G. biloba is temperature, the annual average temperature of $6.86{ }^{\circ} \mathrm{C}$, lower than the general cultivation area, which makes the ground temperature too low. The ground temperature significantly affected the development of the G. biloba root system. Studies have shown that at a depth of $25 \mathrm{~cm}$ underground, new roots appear above $12{ }^{\circ} \mathrm{C}$, new roots are most common at $15-18{ }^{\circ} \mathrm{C}$, but growth is slower than $20^{\circ} \mathrm{C}$ (Yaroshchuk, 2016). In Ukraine, the average temperature is only above $12^{\circ} \mathrm{C}$ from May to September, which means that the Ukrainian G. biloba roots do not grow most of the time. The optimal growth temperature is only June and August. The average temperature in Zhuji from April to November is above $12{ }^{\circ} \mathrm{C}$, which means that the growth time of Zhuji G. biloba is 2-3 times that of Ukrainian G. biloba. From the variance and the dispersion coefficient, we can find that in Ukraine, the temperature variation is higher due to hot and cold weather, especially in the spring, which will seriously affect the germination and flowering pollination of G. biloba. Therefore, stable temperature conditions are more conducive to the growth and development of G. biloba.

There is no direct relationship between ground temperature and air temperature. The direct heat source of the atmosphere is the ground. However, the higher the altitude is, the farther away it is from the ground, the less radiation it receives and the lower the temperature. Obviously, the ground temperature in summer and daytime is higher than the atmospheric temperature, and the atmospheric temperature in winter and night is higher than the ground temperature. Under normal conditions, the difference between the air temperature and the ground temperature is $1.6-2.3^{\circ} \mathrm{C}(\mathrm{CaO}, 2007)$. Therefore, the growth time of G. biloba trees in Ukraine may be shorter. Furthermore, extreme cold weather occurs in winter in Ukraine, and in the north, extremely low temperatures can reach minus $30^{\circ} \mathrm{C}$, which is a severe threat to G. biloba trees growing in the wild. G. biloba has a high moisture requirement and can adapt well to the range of non-stop precipitation. From the distribution range of G. biloba in China, the annual precipitation range is 300-2000 mm. Therefore, precipitation in Ukraine can meet the regular growth needs of G. biloba. It prefers a humid air environment, and Ukraine's air humidity is low, especially during the winter and spring seasons.

Sumy region climate characteristics are hot and rainy in summer, mild and humid in winter. According to their conclusion, the prospect of cultivation of G. biloba in the northeastern part of Ukraine is not optimistic. Nevertheless, the cultivation of G. biloba takes place in SNAU lasts several years.

Studies on the condition of plantations in the current two years showed that plant height increased by $45 \%$, annual growth by $30 \%$, the number of leaves increased by $45 \%$, and the diameter of the shoot increased in 2019 three times compared to 2018.

In China, G. biloba leaves have been used for medicinal purposes since ancient times. In Europe and the United States, active study and medicine application began in the mid-twentieth century (Mohanta et al., 2014; Heinonen \& Gaus, 2015; Krauss et 
al., 2016; Badore et al., 2017).

Studies conducted at SNAU showed that G. biloba plants had a larger leaf blade area in the variant with artificial shading of plantations. A comparative analysis between G. biloba leaves from China, and Ukraine found that agronomic techniques with plantation shading increased the leaf blade area. On average, the leaf blade area of leaves from China was $40.89 \mathrm{~cm}^{2}$. The leaves areas of G. biloba from research variants differed significantly from each other and leaves from natural plantations in China. The leaves of G. biloba, which were grown in open ground without shading (V1), had a leaf blade area of $36.11 \mathrm{~cm}^{2}$ and, accordingly, was less than the area of leaves from China by $12 \%$. The area of $44.92 \mathrm{~cm}^{2}(13 \%$ more than the leaves from China) had leaves collected from plants grown in the open ground with shading in SNAU (V2). The leaves of G. biloba plants grown in SNAU in a greenhouse with shading (V3) had the largest leaf blade area among all the studied samples $-56.59 \mathrm{~cm}^{2}$, compared with China's leaves, the difference was about $30 \%$.

Based on data obtained in northeastern Ukraine, growing G. biloba seedlings in open soil without agricultural netting can be recommended, which is very useful and cheap. In this way, it is possible to grow G. biloba plants for decorative purposes.

The best variant to obtain medicinal raw materials is growing with shading. Plants grown in a greenhouse have shown the best results in leaf blade area, even compared to plants from natural plantations in China, although this method is quite expensive. Therefore, given that the leaves of G. biloba are the primary medicinal raw materials, to obtain it, we can recommend agricultural techniques for growing plants in the open ground with the use of agricultural netting, which is economically viable.

\section{Conclusions}

G. biloba has many values, especially landscaping and medicinal value. Ukraine has a vast land, wide black soil area, complex and diverse terrain, and advanced agricultural and forestry production experience. However, in addition to these natural conditions, the Ukrainian G. biloba forest is less distributed and has a single variety. A small amount of G. biloba is only used for ornamental purposes in botanical gardens and lacks effective management and cultivation.

Studies of plant life and annual nature have shown the possibility of growing G. biloba in Ukraine. Climatic conditions of Ukraine as a whole and the Sumy region are favorable for introducing this relict species and its efficiency and cost-effectiveness conduct research on the cultivation of G. biloba plants in natural conditions. Due to the G. biloba resistant to soot, harmful gases and radiation resistance, the plant can be used to landscape chemical plants and cities and be planted in areas with serious soil erosion and improving the soil.

These relict plants' forests can also be attractive in the development of new tourist routes for educational purposes or recreation.

A comparative analysis of plant leaves from natural plantations from China and cultivated in the experimental plots of the Sumy National Agrarian University (Sumy, Ukraine) showed that the agronomic technique with the shading of plants has a positive effect on increasing the area of the leaf blade. We suggested that this increases the economic efficiency of obtaining medicinal raw materials in leaves of greater mass from earlier age plants.

Thus, considering biological and ecological value, adaptive properties, and developed agrotechnical methods, G. biloba introduction has broad prospects in different Ukraine regions.

\section{References}

Badore, N. S., Das, P. K., Pillai, S., \& Thakur, A. (2017). Role of Ginkgo biloba extract, against isoproterenol induced cardiac toxicity in rats. Indian Journal of Pharmaceutical Education and Research, 51(4), 691-699.

Cai, J., Zhao, P., \& Liu, J. (2018). Ginkgo tree planting technology and management measures. Modern Rural Science and Technology.

Cao, F. (2007). Chinese Ginkgo biloba. Chinese Forestry Publishing House (in Chinese).

Chauhan, J. M. S., \& Maneesh, S. B. (2019). Effect of hormonal concentration on rooting behavior of Ginkgo biloba L. in agroclimatic zone of Dehradun, Uttarakhand, India. Tropical Plant Research, 6(2), 306-311. doi: 10.22271/tpr.2019.v6.i2.039

Chen, Y. (2013). The Value of Ginkgo and Its Seedling Breeding Technology. Modern Agricultural Science and Technology, 13, 191-192.

Chinese Flora Committee of CAS. (2006). Chinese Flora. Volume 7. Ginkgo. Science Press, Gazebo.

Ding, J. (1996). Harvesting and Storage of Ginkgo Fruit. Yunnan Agricultural Science and Technology, 4, 47-48.

Gopichand, R. L. M. (2015). Standardization of propagation and agro techniques in Ginkgo biloba L. - a medicinally important plant. Journal of Medicinal Plants Studies, 3(4), 6-15. doi: 10.22271/tpr.2019.v6.i2.039.

Guo, J., Wu, Y., Wang, B., Lu, Y., Cao, F., \& Wang, G. (2016). The effects of fertilization on the growth and physiological characteristics of Ginkgo biloba L. forests, 7(293), 3-14. doi.org/10.3390/f7120293.

Heinonen, T., \& Gaus, W. (2015). Cross matching observations on toxicological and clinical data for the assessment of tolerability and safety of Ginkgo biloba leaf extract. Toxicology, 327, 95-115. doi: 10.1016/j.tox.2014.10.013.

Jacobs, B. P., \& Browner, W. S. (2000). Ginkgo biloba: A Living Fossil. The American Journal of Medicine, 108, 341-342. doi: 10.1016/s0002-9343(00)00290-4.

Kovalenko I. M., Klymenko G. O., Yaroschuk R. A., Fedorchuk M. I., Lykholat O. A. (2018). Optimization of Ginkgo biloba cultivation technology in open soil conditions. Regul. Mech. Biosyst., 9(4), 535-539. doi: 10.15421/021880

Kovalenko, I. M., Klymenko, H. O., Yaroshchuk, R. A., \& Su, Y. (2019). Osoblyvosti vitalitetnoi struktury nasadzhen Ginkgo biloba L. v umovakh Pivnichnoho Skhodu Ukrainy [Features of vitality structure of Ginkgo biloba L. plantations in the conditions 
of the North-East of Ukraine]. Ahronomiia i Biolohiia, 4(38), 66-71 (in Ukrainian).

Krauss, P., Tziridis, K., Buerbank, S., Schilling, A., \& Schulze, H. (2016). Therapeutic value of Ginkgo biloba Extract EGb 761 ${ }^{\circledR}$ in an animal model (Meriones unguiculatus) for noise trauma induced hearing loss and tinnitus. PLoS ONE, 11(6), e0157574. https://doi.org/10.1371/journal.pone.0157574

Li, H.L. (1956). A horticultural and botanical history of Ginkgo. Morris Arboretum Bulletin, 7, 3-12.

Mahadevan, S., \& Park, Y. (2008). Multifaceted Therapeutic Benefits of Ginkgo biloba L.: Chemistry, Efficacy, Safety, and Uses. Journal of food Science, 73(1), 14-18. doi: 10.1111/j.1750-3841.2007.00597.x.

Mohanta, T. K., Tamboli, Y., \& Zubaidha, P. K. (2014). Phytochemical and medicinal importance of Ginkgo biloba L. Natural product research, 28(10), 746-752. doi: 10.1080/14786419.2013.879303.

Rimkiene, L., Kubiliene, A., Zevzikovas, F., Kazlauskiene, D., \& Jakstas, V. (2017). Variation in flavonoid composition and radicalscavenging activity in Ginkgo biloba L. due to the growth location and time of harvest. Journal of Food Quality, ID 6840397. https://doi.org/10.1155/2017/6840397.

Schmid, W., \& Balz, J. P. (2003). Cultivation of Ginkgo biloba L. on three continents. III WOCMAP Congress on Medicinal and Aromatic Plants, 2, 177-180. doi: 10.17660/actahortic.2005.676.23.

Seward, A.C. (1938). The story of the maidenhair tree. Science Progress, 32(127), 420-440.

Shi, J. (1992). Preliminary study on ecological characteristics of Ginkgo biloba. Journal of Guizhou Agricultural Sciences, 3, 48-52.

Singh, B., Kaur, P., Gopichand, R. L. M., Singh, R. D., \& Ahuja, P. S. (2008). Biology and chemistry of Ginkgo biloba. Fitoterapia, 79(6), 401-418. doi: 10.1016/j.fitote.2008.05.007.

Su, Y., \& Klymenko, H. (2019). Ginkgo biloba L. in China. Materials of NPK of teachers, graduate students and students of SNAU, 28.

The IUCN Red List of Threatened Species. (2018). IUCN Red List of Threatened Species. Available from: https://www.iucnredlist.org/

Xing, S., Zhang, Q., Fu, Z., Liu, L., Liu, X., Xin, H., \& Wu, Q. (2013). Ontogenesis and systematics implications of Ginkgo biloba Chichi. Scientia Silvae Sinicae, 49(8), 108-116.

Xu, J. (2001). Zhejiang Ancient Ginkgo. National Land and Green Journal, 2, 30-31.

Yaroshchuk, R. A. (2016). Perspektyvy vyroshchuvannia Ginkgo biloba L. v umo-vakh pivnichno-skhidnoho lisostepu Ukrajiny dlia zahotivli lystia u farmatsev-tychnykh tsiliakh [Prospects of cultivation of Ginkgo biloba L. in the conditions of the NorthEastern Forest-Steppe of Ukraine for harvesting leaves for phar-maceutical purposes]. Ahronomiia i Biolohiia, 32, 124-128 (in Ukrainian).

Yoshikawa, T., Naito, Y., \& Kondo, M. (1999). Ginkgo biloba leaf extract: review of biological actions and clinical applications. Antioxidants and redox signaling, 1(4), 469-480. doi: 10.1089/ars.1999.1.4-469.

Zhao, Y., Paule, J., Fu, C., \& Koch, M. A. (2010). Out of China: Distribution history of Ginkgo biloba L. Taxon, 59 (2), 495-504. doi: $10.1002 / \operatorname{tax} .592014$

Zlobin, Ju. A., Skljar, V. G., \& Klimenko, A. A. (2013). Populjacii redkih vidov rastenij: teoreticheskie osnovy i metodika izuchenija [Populations of rare plant species: theoretical foundations and methods of study]. Universitetskaja kniga, Sumy. (in Russian).

\section{Citation:}

Kovalenko, I.M., Klymenko, G.O., Melnychuk, S.D., Skliar, lu.L., Melnyk, O.S., Kyrylchuk, K.S., Bondarieva, L.M., Zubtsova, I.V., Yaroshchuk, R.A., Zherdetska, S.V. (2020). Potential adaptation of Ginkgo biloba - comparative analysis of plants from China and Ukraine.

Ukrainian Journal of Ecology, 10(6), 329-337.

(cc) EY This work is licensed under a Creative Commons Attribution 4.0. License 